\title{
correspondence
}

\section{Newton and Kepler}

Sir, - The exchange of letters between J. Herivel and D. T. Whiteside (Nature, April 19, 634) arising from Herivel's review of my Introduction to Newton's Principia (Nature, 247, 163-4), hinges primarily on my alleged interpretation of an article by Whiteside (1964) and only secondarily on the substantive issue: Isaac Newton's possible knowledge of Kepler's law of areas before, 1676 or so, or even later.

When Whiteside's article appeared in 1964, I had already been engaged for several years in wholly independent research on the development of planetary astronomy before the Principia and on the source of Newton's knowledge of Kepler's laws. One of the central topics of my investigation had been the use of one of three then-current variant substitutes for (or approximations to) the area law--associated with the names of Bullialdus, Ward and Mercator. As I read through Newton's early manuscripts and book annotations, I was struck by the fact (it would have been impossible not to have been!) of the obvious and conspicuous lack of any early documentary reference by Newton himsclf to the law of areas-there is none dating from the period up to the famous exchange of letters hetween Hooke and Newton in 1679-80.

When Whiteside's brilliant article appeared, I temporarily laid aside my own book-length manuscript, but the postscript (page 137) to Whiteside's article refers to this work of mine. Accordingly, Herivel's remarks as to whether my opinion is or is not simply a correct interpretation of Whiteside's article may be seen to be irrelevant.

The substantive point at issue is not whether Newton may possibly have encountered the law of areas before 1676 (at which time he may very well have read the statement of the law in Mercator's treatise). It is rather whether at any time earlier than the end of his exchange of letters on motion with Hooke, in 1678-79, Newton consciously gave to this law any serious consideration as a possible basis of physical principles, or as an accurate (or most accurate) descriptive statement of the variations in planctary orbital speeds, or even as a major or significant element in considering planetary motions of the same order of importance, say, as the elliptical orbits or the harmonic law. On the basis of ordinary canons of historical evidence, and to give my view the most accurate expression possible, the footnote in my Introduction, which is the occasion for these letters may be (in part) expanded and rewritten more fully so as to read:

"There is no documentary evidence that Newton was consciously aware of Kepler's law of areas (much less that he considered this law in any significant manner) prior to 1676 , when he might well have encountered it in Mercator's Institutionum Astronomicarum Libri Duo. At the end of his correspondence on motion with Hooke in 1679-80, or possibly soon thereafter, but at least by 1684, he used this law to solve the central problem of elliptical planetary motion, shown to result from the action of a centrally directed inverse-square force on a body with a component of linear inertial motion."

Yours faithfully,

\section{Bernard Cohen}

Cambridge, Massachusetts

\section{Family planning}

SIR,-Poor parents in poor countries do not readily adopt family planning methods even when these are available to them, because they do not want to have small families. They want large families for various reasons, many of which are economic; children provide free labour on family farms, security in old age and so on. Economic motivations can be changed by economic means. Under present circumstances a substantial reduction in the rate of population growth appears to depend on widespread economic improvement: but in many developing countries widespread economic improvement does not seem feasible unless there is a substantial reduction in the rate of population growth.

The problems are familiar, but they may not be insoluble. In many parts of the world the parents' desire for large families seems to represent to a great extent a desire for sons. If such parents could choose to have sons rather than daughters they would probably do so; if a cheap and simnle method existed which increased the chances of having sons rather than daughters, it would probably be readily adopted. The total number of children needed in order to obtain any given number of sons would be reduced. And in the long term, the shortage of women of child-bearing age would lead to a further reduction in the birth rate.

Human sperm bearing $X$ and $Y$ chromosomes can be separated in vitro on the basis of their differential motility. Y-sperm, which are maledetermining, have a greater ability to penetrate an interface between a less viscous and a more viscous fluid and also out-distance $\mathrm{X}$-sperm by swimming faster in a fluid of relatively high density and viscosity ${ }^{1}$. It is not inconceivable that some method could be devised whereby a suitable viscous solution could be introduced (for example within a capsule) into the female genital tract in such a way that after sexual intercourse the X-sperm were selectively retarded and the chances of conceiving a male child were increased.

The idea that the ability of parents to choose to have sons rather than daughters could lead to a substantial reduction in the birth rate, especially in countries with high rates of population growth, has been proposed before?; the recent findings on differential sperm motility suggest that this idea should now be taken seriously.

If a suitable method could be developed and if it were adopted on a wide scale, the increased proportion of males in the population would undoubtedly create new problems, some of which are casy to imagine. But what are the imaginable alternatives? In India, for example, in spite of a wellestablished, government-sponsored family planning organisation and mass sterilisation programme, the population is now increasing by one million every twenty-five days.

Yours faithfully,

\section{A. R. Shei.JRAKE}

International Crops Research Institute for the Semi-Arid Tropics (ICRISAT). 1-11-256 Begumpet,

Hvderabad 500016,

$A P$, India

' Ericsson, R. J., Langerin, C. N., and Nishino, M., Nature, 246, 421-424 (1973).

2 Postgate. J., New Scientist, 12-16 (April 5, 1973). 